\title{
pro.posições
}

$e$-ISSN 1980-6248

http://dx.doi.org/10.1590/1980-6248-2017-0057

ARTIGOS

\section{Políticas educacionais antirracistas na América Latina: estudos comparados}

\section{Anti-racist educational policies in Latin America: comparative studies}

\section{Políticas educativas antirracistas en América Latina: estudios comparativos}

Wellington Oliveira dos Santos (i)

(i) Universidade Estadual de Goiás - UEG, Formosa, GO, Brasil. https://orcid.org/0000-0002-32892483,wellpsico@gmail.com

Resumo: Neste texto, tem-se por objetivo apresentar um quadro dos estudos comparados existentes sobre políticas educacionais antirracistas na América Latina, com foco na população negra. Realizou-se a pesquisa em bases de dados online, encontrando seis trabalhos sobre o tema, tendo como foco principalmente Brasil e Colômbia. Ainda que os estudos destaquem que os negros na América Latina enfrentam dificuldades semelhantes no campo educacional, é alarmante a falta de estudos comparados sobre essa população na região, o que pode estar relacionado à falta de dados estatísticos baseados em critérios raciais.

Palavras-chave: educação, população negra, América Latina

Abstract: This article aims to present an overview of the existing comparative studies on antiracist educational policies in Latin America, focusing on the black population. The research was conducted on online databases and found 06 papers on the subject, focusing mainly on Brazil and Colombia. Although studies point out that black people in Latin America face similar difficulties in the educational field, the lack of comparative studies on this population in the region is alarming and may be related to the lack of statistical data based on racial criteria.

Keywords: education, black population, Latin America 


\section{pro.posições}

$e$-ISSN 1980-6248

http://dx.doi.org/10.1590/1980-6248-2017-0057

Resumen: En este trabajo nuestro objetivo es proporcionar un marco a los estudios comparativos existentes en las politicas educativas contra el racismo en América Latina, centrado en personas de raza negra. Realizamos una investigación en bases de datos en línea y encontramos seis documentos sobre el tema, con eje principalmente en Brasily Colombia. A pesar de que los estudios ponen de manifiesto que las personas negras en América Latina enfrentan dificultades similares en el campo de la educación, es alarmante la falta de estudios comparativos sobre esta población en la región, lo que puede estar relacionado con la falta de datos estadísticos basados en criterios raciales.

Palabras clave: Educación, población negra, América Latina

\section{Introdução}

Neste texto, temos por objetivo apresentar um quadro dos estudos comparados existentes sobre políticas educacionais antirracistas na América Latina, com foco na população negra. Entendemos que políticas educacionais antirracistas são aquelas que buscam contribuir para a superação do racismo no contexto educacional, combatendo formas de hierarquização, discriminações e preconceitos presentes no currículo e nas práticas escolares, e promovendo positivamente grupos minoritários.

A reflexão faz sentido no contexto atual, uma vez que países como Brasil, Colômbia e mais recentemente Uruguai adotam várias formas de políticas antirracistas com foco em suas populações negras, respondendo às reivindicações de militantes negros e estudiosos e também respeitando acordos internacionais. Tal reflexão está inserida na discussão sobre o racismo presente nas sociedades latino-americanas e as maneiras de superá-lo.

\section{Racismo e colonialidade do poder na América Latina}

O fenômeno racismo, como conhecemos, como ideologia usada para justificar a superioridade de grupos humanos sobre outros, existe desde os séculos XVI e XVII. (Quijano, 2005; Telles, 2003). Na colonização, ele foi utilizado como justificativa para o 


\section{pro.posições}

$e$-ISSN 1980-6248

http://dx.doi.org/10.1590/1980-6248-2017-0057

domínio dos povos europeus sobre os povos considerados atrasados da América e da África. Ou seja, o racismo, quando surge, vem para justificar a dominação dos europeus diante dos povos "selvagens" e diante deles mesmos. Sendo os europeus a raça superior, não haveria questionamento moral de seu fardo: civilizar os povos não civilizados.

Entre as formas de dominação dos povos "não civilizados", estava a escravidão. A escravidão precisava da justificativa baseada na superioridade da raça, associada à cor de pele (ainda que não fosse utilizado o termo racismo). Raça, então, foi o primeiro sistema global de dominação social (Quijano, 2005). Quijano (2005) defende que o capitalismo, primeiro sistema global de exploração, teve na escravidão negra um de seus pilares para a acumulação de capital, já que o capital se desenvolveu na Europa a partir da exploração do trabalho nas colônias, "na escravidão 'negra', que produzia os vegetais preciosos, e na servidão 'índia', produtora dos metais preciosos [ênfases no original]" (p.22).

O colonialismo, que precisava da mão de obra escrava nas colônias das Américas, escravizou civilizações dos grupos indígenas e de cor negra (Quijano, 2005). Isso teve consequências para as regiões tomadas.

Para a América e, em particular, para a atual América Latina, no contexto da colonialidade do poder, esse processo implicou que, à dominação colonial, à racialização, à re-identificação geocultural e à exploração do trabalho gratuito, fosse sobreposta a emergência da Europa Ocidental como o centro do controle do poder, como o centro de desenvolvimento do capital e da modernidade/racionalidade, como a própria sede do modelo histórico avançado da civilização. Todo um mundo privilegiado que se imaginava, se imagina ainda, autoproduzido e autoprojetado por seres da raça superior par excellence, por definição os únicos realmente dotados da capacidade de obter essas conquistas [ênfases no original]. (p.23)

Nessa colonialidade do poder, a racialização dos povos, isto é, a atribuição de qualidades intelectuais, morais ou comportamentais, a partir de traços fenotípicos (cor de pele, formato do nariz e dos olhos, etc.), serve para demarcar quais seres humanos pertencem ao mundo do colonizador e quais pertencem ao mundo do colonizado. Em outras palavras, o uso da raça serve para demarcar quem tem mais e quem tem menos poder. Nesse sentido, as explicações eurocêntricas dos fenômenos históricos, tão comumente difundidas na educação, são consequências dessas relações de poder: a Europa, detentora do poder econômico, bélico, desenvolveu sua forma de racionalidade e a impôs como a única válida (Quijano, 2005), usando durante muito tempo a escravidão. 


\section{pro.posições}

$e$-ISSN 1980-6248

http://dx.doi.org/10.1590/1980-6248-2017-0057

Nas Américas, os autoproclamados colonizadores saquearam, destruíram e tornaram escravas inúmeras grandes civilizações. Na África, os colonizadores agiram como caçadores, capturando homens e mulheres a serem vendidos como mercadoria valiosa. Uma vez em solo estrangeiro, negros estiveram sujeitos ao domínio dos europeus. Mas encontraram formas de resistência. Na Colômbia, por exemplo, os palenques, formados desde o século XVI, preservaram não apenas a liberdade e a dignidade de seus habitantes, mas também sua tradição e cultura.

Ao longo do século XIX, graças à falência do modo de produção escravista, às lutas de independência, à pressão inglesa e aos movimentos abolicionistas dos negros, os países latinoamericanos (e caribenhos) aboliram a escravidão. O fim da escravidão, entretanto, não marca o fim do racismo. As crenças raciais, que antes eram apoiadas apelando para interpretações bíblicas, posteriormente foram apoiadas pelo racismo científico, que foi, literalmente, a busca por bases científicas para justificar as desigualdades entre diferentes grupos de cor. Intelectuais apelavam para interpretações do darwnismo para justificar o atraso dos "povos de cor" no capitalismo global.

Frantz Fanon (1979) argumenta que a dominação também ocorre no nível da consciência dos povos colonizados. Permanece um complexo de inferioridade na mentalidade das ex-colônias: a ideia de que o mundo do colonizador (europeu) é superior ao colonizado, uma vez que é útil ao colonizador manter esse aspecto. O colonizado, negro, introjeta a dominação, negando-se como sujeito de cultura e história, tentando ser um negro-branco. Dentro da lógica do colonialismo, a violência do colonizador é justificada com a ideia de que, ao levar civilização aos colonizados, estaria arrancando-o do atraso material e intelectual; em outras palavras, protegendo-o dele mesmo.

Como afirma Quijano (2005), a colonialidade do poder na América Latina (AL), se não mais marcada pela histórica dependência material da Europa, agora é estabelecida por suas relações subjetivas e intersubjetivas com a chamada Europa Ocidental. Nessa lógica, europeus e seus descendentes, onde quer que fossem e estivessem, manteriam seus privilégios diante dos colonizados.

Sobre os povos negros “colonizados”, Costa (2012) apresenta quatro grandes regimes de desigualdade que abrangeram historicamente essas populações na AL: 1) regime de 


\section{pro.posıções}

$e$-ISSN 1980-6248

http://dx.doi.org/10.1590/1980-6248-2017-0057

escravidão (até metade do século XIX, negros eram tratados como mercadoria); 2) nacionalismo racista (no início do século XX, negros eram considerados ameaça ao avanço da civilização, e os Estados buscavam o branqueamento, simbólico ou real, da população); 3) nacionalismo mestiço (ocorreu em meados do século XX: invocação do discurso de "somos todos mestiços" que, se por um lado trata todos como iguais, por outro gera desigualdade ao ignorar os séculos de exclusão da população negra e as práticas racistas); e 4) regime compensatório.

Os regimes compensatórios, do fim do século XX, de acordo com Costa (2012) têm como principal lógica de estratificação (que também é uma lógica de redistribuição) o destaque de uma população-alvo das políticas compensatórias, bem como alianças antirracistas internacionais (por exemplo, a III Conferência Mundial contra o Racismo, a discriminação racial, a xenofobia e a intolerância correlata, em Durban, no ano de 2001, na qual os países signatários se comprometem a adotar medidas de ação afirmativa tais como a valorização da história e da cultura dos grupos étnico-raciais minoritários na educação) e influência de organizações multilaterais. Apesar da emergência de regimes compensatórios na história dos regimes de desigualdade da AL, que podem significar, em determinados contextos, vantagens para os afrodescendentes, Costa (2012) alerta que ainda têm força na região os discursos do nacionalismo mestiço, que celebram a mestiçagem de maneira ambígua e relegam, usualmente, os afrodescendentes a uma posição subalterna.

Diante dessa situação, realizamos o levantamento sobre os trabalhos que tratam do tema legislações educacionais antirracistas e população negra na América Latina. Apresentamos a metodologia a seguir.

\section{Metodologia}

$\mathrm{Na}$ revisão de literatura para a América Latina, buscamos a maior abrangência possível a partir da temática "negro e educação". Estabelecemos, da década de 1980 até os dias atuais (2016), o recorte de produção existente. Partimos da suposição de que existem poucos trabalhos acadêmicos disponíveis sobre o tema "políticas educacionais antirracistas e população negra". 


\section{pro.posições}

$e$-ISSN 1980-6248

Aqui, descrevemos os procedimentos da pesquisa bibliográfica realizada. Dois objetivos básicos desta pesquisa: 1) organizar bibliografia existente sobre dados educacionais e políticas educacionais com foco na população negra da AL; 2) analisar o contexto educacional atual da população negra na América Latina, a partir da bibliografia existente.

$\mathrm{Na}$ pesquisa, utilizamos bases de dados online. Os descritores empregados para as buscas eletrônicas estão no Quadro 1. Combinamos o termo "América Latina" com descritores relacionados ao tema (por exemplo, racismo; educação). Cabe destacar que também utilizamos versões em espanhol e inglês para a pesquisa dos termos.

\section{América Latina +}

Raça; racismo; políticas raciais; ações afirmativas; preconceito racial e educação; políticas educacionais; negros e educação; negros; afrodescendentes e educação; afrodescendentes; educação multicultural; educação multirracial; educação étnica; educação.

\section{Quadro 1 - descritores utilizados para a revisão de literatura América Latina}

Fonte: organizado pelo autor

O período de buscas abrangeu os meses de setembro-outubro de 2013, julho-agosto de 2014, junho-julho de 2015, agosto-setembro de 2016, e dezembro de 2016 e janeiro de 2017. A maior parte das bases de dados em que optamos fazer a busca foi brasileira. São elas: Google Acadêmico, Instituto Nacional de Estudos e Pesquisas Educacionais Anísio Teixeira, Biblioteca Instituto Brasileiro de Informação em Ciência e Tecnologia (IBCT), Edubase, Periódicos Online de Educação, Scientific Electronic Library Online (SciELO, biblioteca eletrônica que abrange ampla coleção de periódicos científicos nacionais relacionados à área da educação, como a Revista Brasileira de Educação e a Revista Brasileira de Ciências Sociais, incluindo dossiês), Periódicos Eletrônicos de Psicologia (Pepsic), Portal Periódicos Capes, Associação Nacional de Pós-Graduação e Pesquisa em Educação (ANPEd).

As bases internacionais foram: Catalogo del Servizio Bibliotecario Nazionale; The Britsh Library; Copac; Bibliothèque Nationale de France; Citas Latinoamericanas en Ciencias Sociales y Humanidades (CLASE); Red de Revistas Científicas de América Latina y El Caribe, España y Portugal (Redalyc); e o Education Resources Information Center (ERIC).

Aqui cabe uma observação metodológica. Cada base de dados utiliza formas específicas de consulta do material. Assim, por exemplo, a Redalyc permitiu busca em campos, 


\section{pro.posições}

$e$-ISSN 1980-6248

http://dx.doi.org/10.1590/1980-6248-2017-0057

o que foi útil para a pesquisa no campo educacional e de humanidades. Outras utilizam buscas gerais, o que aumentou o trabalho necessário para filtrar os textos relevantes. Muitas vezes, usando termos de buscas diferentes, encontramos os mesmos trabalhos. Para a pesquisa, desconsideramos os trabalhos repetidos.

Com a busca, localizamos 88 textos, seja artigos de demanda contínua ou artigos presentes em dossiês. Entretanto, a maior parte dos textos encontrados não dialogava com o campo educacional, o que era esperado, considerada a grande abrangência dos termos de busca utilizados. Optamos por concentrar a análise em textos que tratam do campo educacional: 15, sendo que 06 deles são estudos comparados sobre políticas educacionais antirracistas nos países da $\mathrm{AL}$ e 09 são textos que estudam aspectos da população negra no campo educacional latino-americano.

Considerando que nossa pesquisa foi realizada em base de dados online, é possível que muita produção acadêmica ainda não estivesse disponível no formato digital.

A seguir, apresentamos primeiro o que diz a literatura acerca da população negra no sistema de ensino dos países da AL. Em seguida, exploramos os trabalhos que tratam de estudos comparados sobre as políticas educacionais antirracistas utilizadas nesses países.

\section{Negro e educação na América Latina: o que diz a literatura}

Apresentamos aqui síntese dos trabalhos encontrados em nossa revisão de literatura que discutem a situação educacional do negro na América Latina. Tais trabalhos são relevantes para a análise do contexto de emergência das políticas educacionais específicas para o grupo negro na AL.

Os trabalhos mostram geralmente indígenas e afrodescendentes como marginalizados nas sociedades da AL. Por exemplo, Bello e Rangel (2002) apontam a educação e o acesso às novas tecnologias como uma das formas de democratizar o conhecimento e superar as barreiras sociais, porém alertam:

Pero indigenas y afrodescendientes han sido excluidos por igual no sólo del acceso a los bienes materiales y simbólicos, a los cuales el conjunto de la sociedad debiera tener iguales oportunidades de acceso, sino que también de los procesos de adquisición o reconocimiento de sus derechos especificos. El derecho a una identidad propia, a 


\section{pro.posıções}

$e$-ISSN 1980-6248

http://dx.doi.org/10.1590/1980-6248-2017-0057

una lengua y una cultura forman parte del repertorio de demandas que se agregan a las de tipo económico y socialy que se enlazan con la adquisición de derechos politicos como marco regulatorio y legitimador. (p.42)

Existem dificuldades de acesso a dados acerca das populações negras de países da América Latina devido a, entre outras coisas, ausência de censos demográficos que caracterizassem as populações por cor/raça (Bello \& Rangel, 2002). Na época em que escreveu o seu texto, era possível apenas estimar a população negra de alguns países, por exemplo, 20\% Colômbia, 10\% Venezuela e 16\% na região do Caribe (Bello \& Rangel, 2002). A ausência de dados que diferenciam as populações por cor/raça acaba encobrindo desigualdades entre os grupos raciais.

Streck (2006), ao tratar da relação entre práticas educativas e movimentos sociais na América Latina, também argumenta que indígenas e negros, sendo parte silenciada da sociedade, recentemente têm em seus movimentos sociais a valorização de sua história e seus valores, o que pressupõe práticas educativas.

Dos poucos dados segregados por cor ou raça, Di Pierro (2008) discute em parte aqueles relacionados ao analfabetismo, a partir de dados da UNESCO de países da AL. O analfabetismo entre as pessoas com 15 anos ou mais atinge de maneira desigual os grupos étnico-raciais na Colômbia. A taxa média de analfabetismo da população é de 7,9\%, enquanto que entre os afro-colombianos é de $13 \%$ e entre os indígenas 17,7\% (Di Pierro, 2008). O mesmo cabe para o Brasil, onde o analfabetismo é de 16\% entre os negros contra 7,1\% entre os brancos e $13 \%$ da população geral.

Os dados sobre o analfabetismo, divulgados pela Unesco, já revelam como a Colômbia e outros países da AL têm falhado em cumprir acordos internacionais de combate às desigualdades entre grupos raciais. Gentili (2009) discute em seu artigo, entre outras coisas, como a Declaração Universal dos Direitos Humanos, proclamada pela Assembleia Geral da ONU em 1948, apesar do avanço alcançado em suas aspirações igualitárias que influenciam declarações, acordos e tratados internacionais sobre os direitos humanos, está distante de ser cumprida na prática. A pobreza e as desigualdades existentes em países da América Latina, tais como o racismo, impedem a concretização desse direito Gentili (2009): “A maior probabilidade de estar excluído da escola ou de ter acesso a uma escolaridade profundamente degradada em suas condições de desenvolvimento pedagógico é ter nascido negro, negra ou indígena, em qualquer país da América Latina ou do Caribe” (p.1067). 


\section{pro.posıções}

$e$-ISSN 1980-6248

http://dx.doi.org/10.1590/1980-6248-2017-0057

Uma das mais eloquentes evidências das desigualdades educacionais na América Latina é a persistência do racismo na educação (Gentili, 2009), justamente em sociedades que, em geral, defendem o discurso da mestiçagem e da democracia racial, o que os dados de analfabetismo apresentados por Di Pierro (2008) corroboram. Mesmo com certa melhora de acesso da população negra e indígena à educação e a permanência nela, a distância desses dois grupos raciais para os grupos dominantes não diminuiu:

O racismo educacional persiste na América Latina mediante processos de discriminação pedagógica e curricular, como evidenciaram diversos estudos e pesquisas, assim como em uma constante e tenaz segregação sofrida por esses grupos [negros e indígenas] na qualidade e na quantidade de suas oportunidades educacionais. (Gentili, 2009, p.1068)

O racismo educacional persistente tem sido alvo de algumas políticas educacionais, entre elas as políticas de interculturalidade. Candau (2010) afirma que o conceito de interculturalidade vem ganhando relevância na América Latina a partir dos anos de 1990. Tendo como base a sua revisão bibliográfica sobre o tema, ela constatou que o conceito surgiu no contexto educacional vinculado à educação escolar indígena, nos anos de 1970 (Candau, 2010). Essa afirmação está de acordo com a análise que faz Hooker (2006), quando aponta que na reivindicação das minorias raciais da América Latina, incluindo o campo educacional, os grupos indígenas conseguiram melhor sucesso do que os afrodescendentes; tal fato, segundo a autora, não está relacionado ao tamanho da população, e sim à identidade, ou melhor, à capacidade dos grupos indígenas de apresentar uma identidade étnico-cultural distinta da identidade nacional.

Além da educação escolar indígena, outros grupos contribuíram para a discussão de educação intercultural, como exemplo os negros. No caso desse grupo, a militância começa por buscar desconstruir o conceito de democracia racial e promover leituras alternativas da presença do negro na América Latina para superar estereótipos (Candau, 2010). Também demandam ao Estado ações de reparação, como medidas de ingresso e permanência no sistema de ensino e valorização da cultura afrodescendente (Candau, 2010).

Nesse sentido, Candau e Russo (2010) em seu artigo argumentam, entre outras coisas, que a educação intercultural na América Latina parte das preocupações com a educação escolar indígena. $\mathrm{O}$ movimento negro também entraria na disputa, que pode ser vista como 


\section{pro.posições}

$e$-ISSN 1980-6248

disputa por reconhecimento e visibilidade, uma vez que a educação na América Latina se desenvolveu e se mantém marcada pelo eurocentrismo:

A construção dos estados nacionais no continente latinoamericano supôs um processo de homogeneização cultural em que a educação escolar exerceu um papel fundamental, tendo por função difundir e consolidar uma cultura comum de base ocidental e eurocêntrica, silenciando e/ou inviabilizando vozes, saberes, cores, crenças e sensibilidades. (p.154)

Com relação aos negros, as autoras afirmam:

Apesar da realidade dos grupos e movimentos negros ser muito heterogênea e diferenciada na região, é possível afirmar que esses grupos foram, em geral, reduzidos a uma posição de não cidadania até a metade do século passado. Torna-se necessário lembrar que o regime escravocrata persistiu em alguns países até o final do século XIX.

A situação dos afro-descentes na maior parte do continente tem sido configurada por processos de violência e exclusão física, social e simbólica. No entanto, em diferentes nações, foram muitas as lutas de grupos afro-descendentes por condições de vida dignas e combate à discriminação e ao racismo. Esses grupos têm se caracterizado pela resistência e por suas lutas contra o racismo em suas diferentes manifestações, assim como pela afirmação de direitos e plenitude de cidadania, o que supõe reconhecimento de suas identidades culturais. (p.158)

No entanto, mesmo com essa posição de não cidadania dos negros, foi escassa a produção acerca da educação intercultural de negros na América Latina, pois em geral as informações sobre a educação escolar indígena são abundantes, mas escassas são as que tenham como foco outros grupos da população (Candau \& Russo, 2010). Ainda que os diversos movimentos negros tenham atuado de modo a denunciar a ideologia que privilegia a branquidade/branquitude e inferioriza os grupos não brancos, assim como a apologia à mestiçagem (por exemplo, a democracia racial no Brasil) que mascara as desigualdades entre os diferentes grupos de cor (Candau \& Russo, 2010).

$\mathrm{Na}$ educação, os movimentos negros na América Latina têm lutado por políticas orientadas

ao ingresso, permanência e sucesso na educação escolar, valorização das identidades culturais negras, incorporação nos currículos escolares e nos materiais pedagógicos de componentes próprios das culturas negras, assim como dos processos históricos de resistência vividos pelos grupos negros e suas contribuições à construção histórica dos diferentes países. A valorização da ancestralidade africana constitui um dos elementos fundamentais desta abordagem, principalmente para aqueles grupos que lutam pelo reconhecimento de territórios e neles procuram implementar outros modelos de desenvolvimento. (Candau \& Russo, 2010, p.160) 


\section{pro.posições}

$e$-ISSN 1980-6248

http://dx.doi.org/10.1590/1980-6248-2017-0057

Porém as autoras não aprofundam a discussão sobre quais são essas políticas e quais países da América Latina, além do Brasil, as adotam.

Apesar de não discutir políticas específicas para a população negra, os dados do Unicef analisados por Campos (2012) abrem espaço para pensarmos até que ponto as políticas universalistas, isto é, sem foco racial ou étnico específico, têm diminuído a desigualdades sociais na AL. Campos (2012), em seu artigo acerca de políticas destinadas à educação de crianças de 0 a 3 anos na América Latina, aponta, entre outras coisas, para a universalização crescente no atendimento de crianças com idade mais próxima da educação primária ou fundamental, o que indica maior presença do Estado (tanto na oferta quanto na regulação). Por exemplo, no caso da Colômbia, a Lei Geral da Educação n. ${ }^{\circ} 115$ de 1994 (Ley Colômbia, 1994) estabelece educação obrigatória para crianças a partir da idade de 5 anos; no caso do Brasil, a Lei n. 93.934/96 (Lei BR, 1996) e a Emenda Constitucional n.59-A, de 2009 (Emenda BR, 2009), tornam-na obrigatória para crianças de 4 a 5 anos de idade (vale lembrar: a existência da legislação não significa, necessariamente, que a lei seja cumprida plenamente). Porém a autora destaca que na educação para a faixa etária de 0 a 3 anos existe uma crescente omissão do Estado nos países da América Latina, que transfere a responsabilidade dessa para a sociedade civil. Isso é preocupante, pois, com base nos dados do Unicef, Campos (2012) aponta que

em 2007, 29,2\% (ou seja, 59,2 milhões) de crianças latino-americanas se encontravam em situação de extrema pobreza, pois viviam em lares situados "abaixo da linha da pobreza" com violação de seus direitos básicos; já 15,8\% (28,3 milhões) pertenciam a famílias com rendas mínimas, porém em situação de privação de direitos; por fim, 17,8\% (31 milhões) estavam em situação de pobreza monetária, mas com atendimento de seus direitos básicos. Das crianças que vivem em situação de "pobreza extrema" (29,2\%), em torno de $43 \%$ pertence a "famílias indigentes", situação que atinge, sobretudo, as crianças indígenas e afrodescendentes [ênfases no original]. (p.85)

A resposta de organismos multilaterais como o Banco Mundial, Unesco, Unicef e Cepal para essa "infantilização da pobreza" reside sobretudo na educação, vista como formadora de capital humano necessário para o desenvolvimento produtivo da região e também por estar relacionada a maiores oportunidades de ascensão social (Campos, 2012).

Campos (2012) discorre sobre a educação de crianças pequenas; no outro extremo, Stromquist (2012) fala do Ensino Superior. Ele alerta para o fato de que o processo de 


\section{pro.posıções}

$e$-ISSN 1980-6248

http://dx.doi.org/10.1590/1980-6248-2017-0057

globalização tem dado grande ênfase à Educação Superior, em busca de uma sociedade do conhecimento; porém os países da América Latina estão bem atrasados em relações a outras regiões do planeta, porque, apesar da expansão da Educação Superior (sobretudo via ensino privado), os grupos minoritários, tais como indígenas e afrodescendentes, não tiveram acesso às mesmas oportunidades educacionais que os grupos dominantes. Porém o autor não apresenta dados nesse caso.

Em síntese, dos textos, obtidos em nossa revisão da literatura, que abordam a situação do negro na educação dos países da $\mathrm{AL}$ os que trazem dados quantitativos usualmente apresentam dados gerais acerca do grupo negro no campo educacional, produzidos por organismos internacionais (por exemplo, Campos, 2012; Di Pierro, 2008). O papel de tais instituições na cobrança dos países da região para que superem as desigualdades raciais no campo educacional é discutido em alguns trabalhos (Campos, 2012). Os que falam da questão das desigualdades no campo educacional refletem como as particularidades de uma educação étnica tiveram início com os movimentos indígenas e como os negros estabeleceram recentemente seu espaço no campo de disputa educacional (Candau \& Russo, 2010).

Uma lacuna observada na nossa revisão foi: poucas pesquisas abordam os dados quantitativos das populações da AL, a partir de critérios de raça ou etnia. Tais dados são relevantes para a discussão acerca do acesso dos grupos aos bens materiais e simbólicos das sociedades; e a pouca presença de pesquisa com esses dados indica que poucos países latinoamericanos realizam estudos oficiais baseados em critérios de cor/raça.

\section{Políticas educacionais antirracistas na América Latina: estudos comparados}

Seis trabalhos discutem diretamente a possibilidade ou a existência de políticas educacionais antirracistas com foco na população negra da América Latina, em perspectiva comparada. São os de Sansone (1998), Miranda (2011), Rodrigues (2012), Corbetta e D’Alessandre (2012), Mendes (2013) e Miranda, Quiñonez e Arboleda (2014). Os títulos dos trabalhos e as principais conclusões estão sintetizados no Quadro 2. 


\section{pro.posıções}

http://dx.doi.org/10.1590/1980-6248-2017-0057

$e$-ISSN 1980-6248

\begin{tabular}{|c|c|c|c|}
\hline Autor(a) & Título & Publicação & Resultados/Considerações \\
\hline Livio Sansone & $\begin{array}{l}\text { "Racismo sem } \\
\text { etnicidade. Políticas } \\
\text { públicas e } \\
\text { discriminação racial } \\
\text { em perspectiva } \\
\text { comparada" }\end{array}$ & Artigo 1998 & $\begin{array}{l}\text { A partir da análise de políticas com foco em minorias } \\
\text { raciais, o autor aponta para duas possíveis posturas do } \\
\text { Estado com relação ao grupo negro: reconhecendo } \\
\text { como minoria racial e criando condições para } \\
\text { melhorar sua ascensão social ou propondo medidas } \\
\text { universalistas, buscando atender a todos os grupos de } \\
\text { igual modo. }\end{array}$ \\
\hline $\begin{array}{l}\text { Silvina Corbetta e } \\
\text { Vanesa } \\
\text { D'Alessandre }\end{array}$ & $\begin{array}{l}\text { "Educación y } \\
\text { afrodescendientes } \\
\text { Hacia un balance en } \\
\text { materia de políticas } \\
\text { educativas" }\end{array}$ & Artigo 2012 & $\begin{array}{l}\text { Os grupos negros na AL têm se beneficiado, ainda } \\
\text { que com restrições, da maior cobertura da Educação } \\
\text { Básica, das políticas educacionais específicas para esse } \\
\text { grupo e da militância que pressiona pelos direitos } \\
\text { educacionais dos afrodescendentes. }\end{array}$ \\
\hline Claudia Miranda & $\begin{array}{l}\text { "Etnoeducação e } \\
\text { dimensões político- } \\
\text { pedagógicas da } \\
\text { diversidade cultural } \\
\text { nas propostas } \\
\text { curriculares do Brasil } \\
\text { e da Colômbia" }\end{array}$ & Artigo 2011 & $\begin{array}{l}\text { As militâncias negras do Brasil e da Colômbia } \\
\text { conseguiram importantes conquistas no campo } \\
\text { educacional a partir de legislações específicas, porém o } \\
\text { avanço de tais políticas ainda encontra resistências } \\
\text { associadas ao racismo presente nesses países. }\end{array}$ \\
\hline $\begin{array}{l}\text { Cristiano } \\
\text { Rodrigues }\end{array}$ & $\begin{array}{l}\text { "Afrolatinidades: } \\
\text { movimentos negros, } \\
\text { Estado e políticas } \\
\text { públicas no Brasil e na } \\
\text { Colômbia" }\end{array}$ & $\begin{array}{l}\text { Capítulo } \\
\text { livro } 2012\end{array}$ & $\begin{array}{l}\text { A partir das Constituições, os movimentos negros de } \\
\text { Brasil e Colômbia vêm obtendo conquistas } \\
\text { legislativas; no caso da Colômbia a segmentação do } \\
\text { movimento negro resulta em conquistas que atendem } \\
\text { apenas parte da população, como a Lei } 115 \text { da } \\
\text { etnoeducação de comunidades palenqueras. Aponta } \\
\text { para a lacuna de estudos comparativos sobre políticas } \\
\text { antirraciais entre o Brasil e os países da América } \\
\text { Latina. }\end{array}$ \\
\hline $\begin{array}{l}\text { Pedro Vítor } \\
\text { Gadelha Mendes }\end{array}$ & $\begin{array}{l}\text { "Ações afirmativas } \\
\text { para } \\
\text { afrodescendentes: as } \\
\text { políticas de reserva de } \\
\text { vagas no Ensino } \\
\text { Superior de Brasil e } \\
\text { Colômbia" }\end{array}$ & Artigo 2013 & $\begin{array}{l}\text { Comparando as ações afirmativas destinadas a } \\
\text { reservas de vagas para estudantes afrodescendentes do } \\
\text { Brasil e da Colômbia, o autor considera que, apesar de } \\
\text { ambos os países passarem a adotar medidas } \\
\text { antirracistas mais contundentes a partir da } \\
\text { Conferência de Durban, o Brasil teve maior avanço } \\
\text { em tais políticas do que a Colômbia. Entre as razões } \\
\text { para tal, o autor aponta a escassez de dados } \\
\text { estatísticos sobre a raça ou a etnia dos estudantes do } \\
\text { Ensino Superior colombiano. }\end{array}$ \\
\hline $\begin{array}{l}\text { Claudia Miranda; } \\
\text { Fanny Milena } \\
\text { Quiñonez Riasco; } \\
\text { Jhon Henry } \\
\text { ArboledaQuiñonez }\end{array}$ & $\begin{array}{l}\text { "Discursos e } \\
\text { propostas } \\
\text { etnoeducativas no } \\
\text { Brasil e na Colômbia" }\end{array}$ & Artigo 2014 & $\begin{array}{l}\text { As propostas etnoeducativas do Brasil e da Colômbia } \\
\text { são comprometidas com a valorização do "outro" do } \\
\text { discurso educacional (o não branco, não europeu, } \\
\text { periférico), que refletem as disputas discursivas nos } \\
\text { diálogos existentes entre movimentos sociais e } \\
\text { Estado. }\end{array}$ \\
\hline
\end{tabular}

Quadro 2 - textos sobre políticas educacionais antirracistas na América Latina

Fonte: organizado pelo autor 


\section{pro.posıções}

$e$-ISSN 1980-6248

http://dx.doi.org/10.1590/1980-6248-2017-0057

A seguir, exploramos mais detalhadamente do que trata cada um dos trabalhos localizados.

Livio Sansone (1998), em seu artigo, escrito na época em que as políticas educacionais antirracistas, tais como as de acesso ao Ensino Superior, ainda não haviam sido implantadas no Brasil, discute, entre outras coisas, medidas de combate ao racismo em países da América Latina. Existiam poucas medidas legislativas de combate ao racismo, assim como poucos estudos que as analisavam (Sansone, 1998).

O autor aponta a Colômbia como o país da região latino-americana que mais havia legislado a favor dos negros. Antes, o antigo ideal de branqueamento da população, até o final do século XIX e início do século XX, foi substituído por um discurso racial de elogio da mestiçagem, semelhantemente ao que ocorreu no Brasil (Sansone, 1998).

O discurso de elogio da mestiçagem, nacionalista, acabou negando as especificidades de indígenas e de negros. Mas existia diferença no modo de tratamento de indígenas e de negros: indígenas eram vistos como categoria a ser protegida, enquanto negros não eram considerados como um grupo étnico à parte. Por esse motivo a relação do indígena com o Estado colombiano é muito mais institucionalizada do que a do negro (Sansone, 1998).

O sistema de relações raciais colombiano apresenta ambiguidades que afetam a politização dos negros (Sansone, 1998). Por isso, o movimento negro colombiano busca definir qualquer pessoa de descendência africana como "negro", almejando uma unidade grupal (Sansone, 1998), o que é uma estratégia também presente no movimento negro brasileiro. Tem tido mais eficácia em sua luta pela reivindicação de territórios ocupados por comunidades negras remanescentes de quilombos (palenques) (Sansone, 1998).

$\mathrm{Na}$ Constituição de 1991 (e principalmente com a Lei 70 de 1993), o movimento negro conseguiu uma importante vitória: reconhecimento de alguns direitos dos negros e definição da Colômbia como país multicultural e multiétnico (Sansone, 1998). Porém Sansone (1998) argumenta que essa vitória da comunidade negra de certa forma emulou as conquistas indígenas no país, ou seja, as conquistas tiveram maior impacto entre as comunidades negras tradicionais (camponesas), o que não seria suficiente, já que apenas uma parte da população negra colombiana seria afetada por essa lei. 


\section{pro.posıções}

$e$-ISSN 1980-6248

Enquanto Sansone (1998) discute políticas de combate ao racismo em geral, e compara países como Brasil e Colômbia, em Miranda (2011), há um foco educacional. A autora, discutindo impactos da adoção da diversidade cultural como eixo norteador para políticas curriculares antirracistas no Brasil e na Colômbia, argumenta que pontos de convergência entre os dois países são as lutas por representação e maior acesso à educação escolarizada (Miranda, 2011).

Assim como a militância negra no Brasil conseguiu a Lei $10.639 / 03$, os negros colombianos obtiveram importantes mudanças em 1993 com a Lei 70 e posteriormente com a Lei Geral da Educação, que instituiu a obrigatoriedade do ensino de história dos afrocolombianos (Miranda, 2011). Porém Miranda (2011) destaca que tais políticas enfrentam resistências comuns, tais como o "discurso da brancura" (que poderíamos chamar de discurso da branquidade ou branquitude, ou seja, que toma o branco como modelo ideal) e o elogio da mestiçagem, como argumenta Sansone (1998). Para superar esse entrave, uma mudança no foco de interpretação das relações raciais nos dois países faz-se necessária (Miranda, 2011).

Por sua vez, Cristiano Rodrigues (2012) analisa em perspectiva comparativa os movimentos negros do Brasil e da Colômbia e as políticas públicas voltadas à população negra desses países, a partir das suas Constituições. Ele afirma que é a partir das novas Constituições de cada país, o Brasil em 1988 e a Colômbia em 1991, que pela primeira vez os grupos étnicoraciais indígenas e negros têm direitos constitucionalmente garantidos no campo da cultura e dos territórios.

As políticas de branqueamento e o elogio da mestiçagem fazem parte do processo histórico de ambos os países. As novas constituições em 1988 e 1991, a Lei 70 e a Lei 10.639/03, seriam indícios de "histórias conectadas". Com o reconhecimento legal e a afirmação desses países como multiétnicos, os grupos sociais afro-colombianos e afrobrasileiros passaram a ter maior campo de negociação com os Estados. Tais movimentos sociais do Brasil e da Colômbia, que ganharam força a partir da década de 1970, têm perspectivas diferentes.

$\mathrm{Na}$ Colômbia, embora a maior parte da população negra viva em áreas urbanas, a hegemonia da face rural e campesina do ativismo negro e sua relação de proximidade com grupos indígenas engendraram políticas de identidade que acentuam o fato de afro-colombianos se constituírem em uma coletividade cultural e étnico-racialmente diferenciada do restante da sociedade, ao mesmo tempo em que mantém estreitas relações com o meio ambiente e 


\section{pro.posições}

$e$-ISSN 1980-6248

território. No Brasil, com a hegemonia do movimento negro de caráter mais urbano e uma população afrodescendente historicamente sub-representada nos espaços de maior prestígio social e econômico, os discursos e estratégias mobilizatórias dos movimentos negros têm procurado ressaltar o caráter de luta pela igualdade. (p.61)

Rodrigues (2012) explica que a existência de culturas negras marcadamente distintas da cultura hegemônica colombiana se deve, entre outras coisas, ao processo de ocupação de territórios após a abolição da escravatura. Por exemplo, no caso dos palenques,

após a abolição da escravatura, ocorrida em 1851, a população negra se dispersou ao longo da costa do Pacífico, juntando-se a palenques (quilombos) existentes ou formando novos assentamentos. Graças a certo isolamento geográfico em relação a regiões mais urbanizadas e desenvolvidas do país (sobretudo a região andina), os afro-colombianos desenvolveram formas simbólico-culturais e materiais de existência distintas daquelas do restante da sociedade. (p.65).

A distinção cultural possibilitou a reivindicação e a conquista de uma política educacional específica para as comunidades negras. Assim, por exemplo, a Lei 115 de 1994, Expansão da Lei Geral da Educação colombiana, que trata da etnoeducação para as comunidades negras

estabelece que a etnoeducação seja inserida dentro do currículo escolar para que comunidades étnicas possam ter acesso a conhecimentos culturais e linguísticos pertinentes à sua história dentro do sistema educacional formal. A lei também propõe a formação de educadores para que sejam capazes de atuar com base nos princípios da etnoeducação. (p.82)

Uma das mais importantes conquistas dos negros na Colômbia, a Lei 70, de certa forma reflete as diferenças de reivindicação dos movimentos negros. Rodrigues (2012) argumenta que ela traz um mimetismo da legislação existente para os grupos indígenas (o que Sansone, 1998, por sua vez, considera emulação), por essa razão seu enfoque acaba sendo mais a terra e o território para as populações palenqueras do que a pluralidade étnica.

Por outro lado, ela apresenta uma importante exceção em termos de América Latina: a reserva de vagas para candidatos oriundos das comunidades negras da qual a Lei trata: "A Lei colombiana é, por exemplo, a única na América Latina a prever um sistema de cotas para que candidatos vindos das comunidades negras possam ser eleitos para o Congresso" (pp.74-75).

Porém, Rodrigues (2012) explicita que as conquistas da Lei 70 não são evidentes para os grupos negros dos centros urbanos. E quanto à aproximação do Estado por parte do movimento negro, decorrente da Lei, ele afirma: 


\section{pro.posıções}

$e$-ISSN 1980-6248

http://dx.doi.org/10.1590/1980-6248-2017-0057

O movimento negro colombiano vive as consequências de sua institucionalização e aproximação com o Estado, em que as imersões de parte de suas lideranças e organizações nos aparatos estatais e sua dependência de recursos impede a consolidação de alianças amplas e de identidades solidárias entre os distintos sujeitos coletivos e suas reivindicações. (p.76)

Devemos considerar, entretanto, que Rodrigues (2012) comenta em parte a etnoeducação destinada às comunidades tradicionais negras, porém pouco aborda a Cátedra de Estudo Afro-Colombianos, política educacional destinada a todos os níveis de ensino. Ainda assim, afirma que os Estados (Brasil e Colômbia) têm sido ineficientes em diminuir as desigualdades entre os grupos de cor, ou seja, a elaboração de leis ainda não teve o impacto esperado (Rodrigues, 2012).

A inclusão social e o reconhecimento dos indígenas e afrodescendentes na América Latina fazem parte de um novo cenário, em que instrumentos normativos internacionais pressionam os Estados para que incluam a demanda desses grupos na agenda pública, sendo a educação entendida como uma via para a cidadania (Corbetta \& D'Alessandre, 2012). Corbetta e D’Alessandre (2012) apresentam três exemplos de instrumentos normativos internacionais que pressionam os Estados: a Convenção 169/89 da Organização Internacional do Trabalho (OIT) (1989), o Pacto Internacional de Direitos Econômicos, Sociais e Culturais (PIDESC) da ONU (1996) e a Conferência de Durban (2001) (Corbetta \& D’Alessandre, 2012).

No artigo, as autoras falam dos avanços nas políticas educacionais para a população negra no Brasil de 2001 a 2009, apresentando dados quantitativos de acesso ao ensino e permanência nele. Corbetta e D’Alessandre (2012) discutem esses dados a partir da percepção dos atores sociais (ativistas dos movimentos negros) do Brasil e também da Colômbia e da República Dominicana, esses dois últimos países, apesar de não terem dados quantitativos apresentados (no caso, segundo os autores, dados de acesso da população negra ao ensino e à permanência nele), têm grande participação de negros, e seus movimentos negros também incluem entre suas bandeias o acesso à educação. Os avanços principais apontados pelos entrevistados de cada país foram as seguintes normativas:

En el caso de República Dominicana se menciona La Ley General de Educación del año 1997 y el establecimiento del Plan Decenal de Educación 2008-2018; el apoyo a los estudiantes provenientes de los sectores sociales más vulnerables además de incorporar como estrategia la transversalización de la perspectiva de género y de los derechos bumanos. Respecto a Brasil, los tres actores entrevistados coinciden en señalar la creación de la Ley 10.639 sancionada en 2003 por el Ejecutivo, según la cual se establece en todas las escuelas primarias y secundarias del país- la enseñanza de la bistoria y la cultura afro. Finalmente en el caso colombiano, las coincidencias de los actores se dan sobre el reconocimiento de las Leyes 70 y 115 de los años 


\section{pro.posıções}

$e$-ISSN 1980-6248

1993 y 1994 respectivamente, donde se establece lo que se ha denominado "politica etnoeducativa para población afrodescendiente". (p.69)

De acordo com as autoras, os entrevistados foram unânimes em apontar que os pontos de conflito giram em torno da execução das normativas, o que não vem ocorrendo como esperado (Corbetta \& D’Alessandre, 2012). Entre os fatores que impedem a execução das normativas, os entrevistados da Colômbia e do Brasil citaram:

recursos financieros insuficientes para capacitar a docentes y para editar materiales pertinentes, formación docente inadecuada, resistencia de los docentes en el dictado del contenido, falta de voluntad politica de los distintos niveles del Estado para la aplicación de las normas en la vida cotidiana de las aulas, entre otros. (p.70)

Para superar esses impedimentos, os entrevistados argumentam que é preciso que os movimentos sociais se apropriem de espaços existentes para impulsionar as ações do Estado (Corbetta \& D'Alessandre, 2012).

No caso das políticas de reservas de vagas para afrodescendentes no Ensino Superior, Mendes (2013), em estudo comparado entre o Brasil e a Colômbia, aponta que a Conferência de Durban, em 2001, foi um importante marco para as políticas antirracistas de ambos os países, porém, enquanto no Brasil diversas políticas de ação afirmativa para ingresso de afrodescendentes no Ensino Superior tiveram início, na Colômbia essas políticas têm encontrado resistência.

$\mathrm{Na}$ Colômbia, assim como ocorreu em inúmeras universidades brasileiras, as universidades que adotam ações afirmativas, como reservas de vagas para afrodescendentes e outras minorias étnicas, o fazem por iniciativa de seus conselhos superiores:

Apesar das nítidas determinações no que tange à criação de políticas específicas para as minorias, ações afirmativas como a reserva de vagas no ensino superior para alunos afrocolombianos e indígenas foram adotadas de maneira pulverizada. A reserva de cotas nas universidades públicas passou a ser adotada desde o final da década de 90 por iniciativa dos conselhos superiores das próprias universidades sob pressão regional das organizações do movimento negro com o apoio de estudos acadêmicos sobre a população afro-colombiana no interior das mesmas universidades públicas. Como consequência dessa fragmentação do processo de adoção das políticas de cotas na Colômbia, temos um quadro diverso de organicidades e aplicações desta ação afirmativa.

Atualmente aproximadamente 13 instituições de ensino superior colombianas contam com algum mecanismo de reserva das vagas para alunos afrodescendentes. São elas: Universidad del Valle, Universidad Nacional de Colombia, Universidad Distrital Francisco José de Caldas, 


\section{pro.posições}

$e$-ISSN 1980-6248

http://dx.doi.org/10.1590/1980-6248-2017-0057

Universidad Pedagógica Nacional, Universidad de la Amazonía, Universidad Tecnológica de Pereira, Universidad del Atlántico, Universidad de Nariño, Universidad de Caldas, Universidad de Córdoba, Universidad del Tolima, Universidad del Magdalena e Universidad del Cauca. ( $p$ p.28-29)

É baixo o número de instituições de Ensino Superior com ações afirmativas de reserva de vagas, pois a ausência de dados estatísticos sobre a população negra impede maiores reivindicações dos afro-colombianos nas universidades (Mendes, 2013). Mesmo nas instituições de Ensino Superior, somente a partir de 2008 teve início a coleta de dados por raça ou etnia, a começar pela Universidade Nacional (Mendes, 2013).

Diante do quadro de políticas etnoeducativas do Brasil e da Colômbia em comparação, Claudia Miranda, Fanny Milena Quiñonez Riasco e Jhon Henry Arboleda Quiñonez (2014) propõem uma reflexão sobre os discursos presentes nas propostas das "Diretrizes nacionais para a educação das relações étnico-raciais" (Brasil) e nos "Lineamentos Curriculares para la Cátedra de Estudios Afrocolombianos" (Colômbia). Para os autores, tais propostas estão comprometidas com a valorização do "outro" no discurso educacional. Considerando o discurso hegemônico que privilegia o branco e o europeu no discurso educacional, o "outro" é o não branco, não europeu, periférico.

Nesse sentido, em sociedades que são classificadas como multiculturais, o deslocamento para outras formas de epistemologia, que incluem a valorização da história e da cultura afrodescendente, contribui para a luta dos direitos humanos. Tais propostas etnoeducativas, entretanto, refletem as disputas discursivas nos diálogos existentes entre movimentos sociais e o Estado (Miranda, Quiñonez, \& Arboleda, 2014).

\section{Considerações finais}

Em síntese, o Brasil e a Colômbia foram os países escolhidos para comparação de políticas educacionais por quatro trabalhos; encontramos um trabalho que buscava diálogo entre as políticas do Brasil, da Colômbia e da Republica Dominicana (Corbetta \& D’Alessandre, 2012), e um entre as situações da Colômbia, da Venezuela, do Peru e do Brasil (Sansone, 1998). Esses trabalhos têm pontos em comum: a aproximação entre o Brasil e a Colômbia, por serem países de grande população negra (Miranda, 2011; Mendes, 2013); a 


\section{pro.posıções}

$e$-ISSN 1980-6248

http://dx.doi.org/10.1590/1980-6248-2017-0057

comparação entre as políticas antirracistas desses países (Miranda, 2011; Miranda, Quiñonez, \& Arboleda, 2014); o papel dos movimentos negros na reivindicação de políticas específicas para o grupo populacional negro (Sansone, 1998; Rodrigues, 2012); as modificações nas legislações (Sansone, 1998). Por outro lado, algumas divergências: Corbetta e D'Alessandre (2012) são as únicas a dar voz aos atores sociais envolvidos nas políticas, apesar de Sansone (1998) e Rodrigues (2012) também discutirem a influência nos movimentos sociais nas legislações do Brasil e da Colômbia. A perspectiva teórica de tais textos, ainda que não explicitada, engloba tanto os estudos pós-coloniais quanto as perspectivas críticas em currículo e educação.

Ainda que atualmente existam diversos estudos sobre políticas educacionais antirracistas brasileiras, surpreende a falta de estudos em outros países da AL com grande participação de população negra (para além do Brasil e da Colômbia). Por exemplo, a Venezuela, que recentemente tem passado por uma crise política, humanitária e econômica; o Equador e o Uruguai. A falta de estudos comparados sobre os negros na região pode estar relacionada à ausência de dados estatísticos baseados em critérios raciais, o que contribui para a colonialidade do poder, conforme argumenta Quijano (2005). Também é visível a falta de textos que discutam o papel da população branca diante dos grupos minoritários, bem como as relações entre as organizações econômicas das sociedades latino-americanas, a educação e o racismo.

É possível afirmar que, adotando políticas antirracistas, o Estado, ao mesmo tempo em que está vinculado ao capitalismo, que é ancorado em racialização e racismo colonial (Quijano, 2005), tenta promover a democracia (Espinoza, 2008). Aqui temos a contradição: em termos ideais, uma sociedade capitalista permite maior mobilidade social do que uma sociedade de castas (o caso das sociedades escravistas). Mas, como os estudos da nossa revisão de literatura têm mostrado, no caso da AL, na prática, que, se os mais pobres têm de fato poucas oportunidades de mobilidade social, os mais pobres que não fazem parte do grupo racial dominante (ou, como diz Quijano, 2005, que pertencem ao mundo dos colonizados), têm ainda menos oportunidades. A promoção da democracia, então, depende de políticas específicas para os grupos étnico-raciais minoritários. 


\section{pro.posıções}

$e$-ISSN 1980-6248

http://dx.doi.org/10.1590/1980-6248-2017-0057

\section{Referências}

Bello, A., \& Rangel, M. (2002) La equidad y la exclusion de los pueblos indigenas y afrodescendientes en America Latina y el Caribe. Revista de la CEPAL,76,39-54.

Campos, R. F. (2012, janeiro/abril). "Política pequena" para as crianças pequenas? Experiências e desafios no atendimento das crianças de 0 a 3 anos na América Latina. Revista Brasileira de Educação, 17(49), 81-105.

Candau, V. M. F. (2010). Educação intercultural na América Latina: diferentes concepções e tensões atuais. Estúdios Pedagógicos, 36(2), 333-342.

Candau, V. M. F., \& Russo, K. (2010). Interculturalidade e educação na América Latina: uma construção plural, original e complexa. Revista Diálogo Educacional,10(29), 151-169.

Corbetta, S., \& D’Alessandre, V. (2012, janeiro/junho). Educación y afrodescendientes Hacia un balance en materia de políticas educativas. Exitus, 2(1), 57-77.

Costa, S. (2012). Desigualdades, interdependências e afrodescendentes na América Latina. Tempo Social, 24(2), 123-145.

Di Pierro, M. C. (2008). Educação de jovens e adultos na América Latina e Caribe: trajetória recente. Cadernos de Pesquisa, 38(134), 367-391.

Espinoza, O. (2008). La relación Estado-educación y el proceso de reforma educacional: una aproximación desde la teoría crítica. Revista Iberoamericana de la educación, 45, 1-13.

Fanon, F. (1979). Os condenados da terra. Rio de Janeiro: Civilização Brasileira.

Gentili, P. (2009) O direito à educação e as dinâmicas de exclusão na América Latina. Educaşão e Sociedade, 30(109), 1059-1079.

Hooker, J. (2006). Inclusão indígena e exclusão dos afro-descendentes na América Latina. Tempo Social, 18(2), 89-111.

Mendes, P. V. G. (2013). Ações afirmativas para afrodescendentes: as políticas de reserva de vagas no Ensino Superior de Brasil e Colômbia. Conselho Latino-americano de Ciências Sociais (CLACSO). Recuperado em 26 de agosto de 2015, de http://biblioteca.clacso.edu.ar/clacso/becas/20131220105935/2.pdf 


\section{pro.posıções}

$e$-ISSN 1980-6248

http://dx.doi.org/10.1590/1980-6248-2017-0057

Miranda, C. (2011). Etnoeducação e dimensões político-pedagógicas da diversidade cultural nas propostas curriculares do Brasil e da Colômbia. In 34 Reunião Anual da Associação Nacional de Pós-Graduação e Pesquisa em Educação, Natal, Rio Grande do Norte.

Miranda, C., Quiñonez, F. M. R., \& Arboleda, J. H. (2014). Discursos e propostas etnoeducativas no Brasil e na Colômbia. Revista de História Comparada, 8(1), 189-211.

Quijano, A. (2005). Dom Quixote e os moinhos de vento na América Latina. Estudos Avançados, 19(55), 9-31.

Rodrigues, C.(2012). Engendrando afrolatinidades: movimentos negros, Estado e políticas públicas no Brasil e na Colômbia. In I. Oliveira (Org.), Relações raciais no contexto social, na educação e na saúde: Brasil, Cuba, Colômbia e África do Sul (pp.59-114). Rio de Janeiro: Quartet.

Sansone, L. (1998). Racismo sem etnicidade. Políticas públicas e discriminação racial em perspectiva comparada. Revista Dados, 41(4),751-783.

Streck, D. R. (2006). Práticas educativas e movimentos sociais na América Latina: aprender nas fronteiras. Série-Estudos - Periódico do Mestrado em Educação UCDB, 22, 99-111.

Telles, E. (2003). Racismo à brasileira: uma nova perspectiva sociológica. Rio de Janeiro: Relume Dumará.

\section{Legislação}

Emenda Constitucional BR n59, de 11 de novembro de 2009. Presidência da República. Casa Civil. Subchefia para Assuntos Jurídicos.

Lei BR n. 9.394, de 20 de dezembro de 1996. (1996, 20 de dezembro). Estabelece as Diretrizes e Bases da Educação Nacional. Diário Oficial da União, seção 1, ano CXXXIV, n. 248.

Ley General de Educacion n. ${ }^{\circ}$ 115, 1994. Ministério de Educacion Nacional de Colômbia.

Submetido à avaliação em 27 de março de 2017; revisado em 10 de outubro de 2017; aceito para publicação em 20 de dezembro de 2017. 